\title{
A Quantitative Study of Chinese Learners' Identities as Reflected in Their Attitudes Toward English Accents
}

\author{
Yan Huang ${ }^{a}$ \\ violinhy@qq.com \\ Department of Foreign Languages, \\ Sichuan University of Science and Engineering \\ \& \\ Asia-Europe Institute, \\ University of Malaya \\ Azirah Hashim \\ azirahh@um.edu.my \\ Asia-Europe Institute, \\ University of Malaya
}

\begin{abstract}
Once an asset owned exclusively by native English speakers (NESs) in inner circle, the native English speaking norms, specifically the standard varieties of British and American English, have been taken for granted as models for non-native English speakers (NNESs) in outer and expanding circles to imitate and approximate to. But this paradigm is under severe attack given the fact that people who use English as a lingua franca (ELF) have far outnumbered NESs. This paper aims to show how Chinese tertiary-level second language (L2) learners perceive different English accents and how their perceptions were related to their identities within the framework of ELF. By means of an online questionnaire survey, data from 574 English major students were retrieved and analysed with the assistance of SPSS 20.0 and Nvivo 11.0. The current study focuses on ambivalence in respondents' attitudes toward different English accents. On the one hand, there was an obvious bias towards NES norms and accents and a strong bias against Chinese-accented English and other NNES accents; on the other hand, there was an emergence of linguistic rights and learner identity experienced by some respondents, which demonstrated itself in highlighting pragmaticity in communication, endorsing L1-accented Chinese identity, and questioning benchmark roles accorded to NES accent standards. The implication of the current study is to acknowledge an urgency of addressing the controversies between the linguistic reality and the prescriptive standards, and between the respondents' hidden appeals for projecting their identity via L1-accented English and highly-acclaimed NES accent models.
\end{abstract}

Keywords: attitude; accent; identity; English as a lingua franca; mainland China

\section{INTRODUCTION}

"Language attitudes permeate our lives" (Garrett, 2010) in a low-profile, lack-of-conscious but tenacious way. Its research has maintained momentum for several decades. The theoretical significance of studying language attitudes may be indicated in two ways. First, research in language attitudes has the capacity in determining how people perceive others in accordance with their linguistic feature. For example, there is surprisingly an exact match of people's prediction of the subjects' personality based on the subjects' traits of voices (Allport \& Cantril, 1934; Pear, 1931), and a bias towards a language variety or a dialect out of the social status

a (Main \& corresponding author) 
and educational level of its speaker (Lambert et al., 1960; Lippi-Green, 1994; Tucker \& Lambert, 1969). Second, such studies also have the potential in predicting people's behavioural disposition, for example, attitudes toward self, the native language group and the target language group were tested positively correlated with attained proficiency, especially in ESL context (Chihara \& Oller, 1978; Oller, Hudson, \& Liu, 1977; Zeinivand, Azizifar, \& Gowhary, 2015). More specifically, favourable attitudes lead to more willingness to accept different accent varieties (Chiba, Matsuura, \& Yamamoto, 1995; Dewaele \& McCloskey, 2015) as well as chances to communicate in a foreign language context (Yashima, 2002; Yashima et al., 2004).

Accent most usually refers to phonological and intonation features which convey the characteristics of distinctively geographic and social influence. Ever since the unravelling of the intricate links between voice and stereotyped personalities, it has become a field of interest in language attitude research. A string of empirical studies have been initiated to investigate people's perceptions of different accents in different demographical contexts (Chiba et al., 1995; Dalton et al., 1997; El-Dash \& Busnardo, 2001; Hansen, Zampini, \& Cunningham, 2019; Luk \& Lin, 2006; Rivers, 2011; Tokumoto \& Shibata, 2011). Respondents in these studies were reported of displaying unanimous preference for native English accents, especially American and British English accents, while bearing reservations in reference to non-native English accents where English is used either as a second language or a foreign language. Other studies (Bian, 2009; Fang, 2015; Sung, 2014, 2016; Y. Wang, 2012) have reported emergent questioning of dogged conformity to NES norms and standards and a growing inclination to project people's special identity by means of their L1-accented English. Accent has been labelled as the last publicly acceptable form of discrimination (Lippi-Green, 1997) and it becomes an issue receiving unprecedented attention against the backdrop that English has been used as a lingua franca accommodating variegated communication needs for different L1s speakers, and in the meantime they have been offered a myriad of identity options in ELF communication (Sung, 2014).

ELF defined by Seidlhofer (2011) is "any use of English among speakers of different first languages for whom English is the communicative medium of choice, and often the only option" and for those speakers when using English they don't think about the United States or England, they only think about the need to communicate. This realisation is very significant, especially in the field of English language teaching (ELT) in that the NES norms, specifically the prescriptive standards of British and American English varieties, once taken-for-granted models for NNESs in the outer and expanding circles to imitate and approximate to have for the first time been brought under attack. The salience of accent which has been reincarnated with the most prominent feature of a particular spoken language and a powerful marker of identity in speech, is even higher in ELF context than in communication among NESs (Jenkins, 2007). Accent variety has been advocated as a means to express L 2 speakers' identity (Jenkins, 2000, 2007; Lindemann, Litzenberg, \& Subtirelu, 2014; Walker, 2010) and any form of imposition of modifying L2 speakers' accent against their desires is an act of undermining their identity (Dalton \& Seidlhofer, 1994).

China, thanks to its enormous number of English learners and English users (approximately 400 million in total), becomes a big player in deciding the development of the English language. Due to the influence of traditional culture and philosophy which lays excessive prominence on standards and correctness, China, being labeled as a "norm-dependent" country in Kachruvian term, fully exemplifies its exonormativity in its allegiance and conformity to English as a Native Language (ENL) norms. This situation is compounded by the government and administrators in terms of the enactment of language policies, and longterm exposure to native speaker materials. Things do not change significantly notwithstanding a progress in both people's evaluation of the newly-emerged localised variety of English and 
the general consensus on its legitimacy in academic world (Gao, 2014; Graddol, 2006; He, 2015; Hu, 2004; Jiang \& Du, 2003), and the accessibility of Lingua Franca Core (Jenkins, 2000) which prioritises intelligibility and attainability in both interethnic communication and in ELT pedagogy. The prerequisite, admittedly, for any attempt at bringing changes to the ongoing language pedagogy and language policy making is to make sure that people's attitudes are in favour of those changes.

Attitude research on different English accents in the context of China so far, however, has not received adequate attention. Even if in rare cases, studies of this kind were either conducted under the framework of SLA where English has long been regarded as a foreign language with NES norms its benchmark standards and NESs' recognition its ultimate purpose (He \& Li, 2009; Xu, Wang, \& Case, 2010), or conducted in contexts where the lingua franca role of English has long been established (e.g. Hong Kong, in Sung, 2014, 2016) or highlyacclaimed (e.g. Beijing, in Bian, 2009; well-developed coasted provinces, in Fang, 2015, 2016; Beijing, in X. Zheng \& Gao, 2017). The current study is to complement the research findings obtained by the aforementioned studies. By setting its research site at an inland provincial university in mainland China, this study intends to investigate to what extent participants' attitudes toward different English accents were under the influence of the emerging ELF environment where there was a growing percentage and diversity of international faculty members and students and the use of English language per se has transformed from course-, exam- and employment-driven to communication- and pragmatic purpose-initiated in that case. To be more specific, the current study as one component of a longitudinal project aims to address the following research questions:

- What are Chinese L2 learners' attitudes toward English accents of their own and of other NES and NNES groups in the framework of ELF?

- And why do they bear these attitudes?

- How do participants' identities intersect with their accent perceptions?

\section{METHODOLOGY}

What is reported in this paper is findings from a questionnaire survey, the initial phase of a one-year longitudinal research project which aims to investigate and explore Chinese tertiarylevel L2 learners' attitude changes toward different English accents, and their identity changes in line with their changing attitudes. In general, data retrieved through close-ended questions and rank ordering open-ended questions were processed through SPSS 20.0 which assists in displaying descriptive statistics and obtaining inferential results. Specifically, the Chi-square test was employed to investigate whether age, gender, grade, duration of English learning and experiences abroad impacted dependent variables in the survey, such as the way they evaluated different English accents, etc. The t-test and one-way ANOVA were also adopted to test the existence of any possible statistically significant differences between or among different groups of respondents. Results from open-ended questions in this survey were categorised and analysed with the help of Nvivo 11.0.

\section{PARTICIPANTS}

The first phase of this research project involved the total population of English major students in the research site. Justifications for selecting English major students in this study are twofold. For one thing, English major students in China compared with their non-English major counterparts have far more chances to be exposed to practices and experiences related to the use of English language which would substantially facilitate individual learners' understanding 
of the roles and functions of English language. For another, English major students are more likely than non-English major students to choose to be language teachers, in particular English language teachers in the context of China. This means that their personal perceptions of and beliefs in English language are of high stakes in that these perceptions and beliefs, either biased or unbiased, would have enduring effect on their potential students in the future. And the situation would not dramatically change even if they opt out teaching profession in that they still incline to choose professions related to their major, English.

\section{DATA COLLECTION}

Data were collected from a comprehensive university situated in Sichuan, a province in southwestern part of mainland China. Enrollments into this university are students from different provinces, municipalities and autonomous regions across China, except Hong Kong, Macao and Taiwan. A point to note is that at the time of the research there was a substantial increase in the number of international students and faculty members at the research site, whose presentation makes English a major auxiliary language or lingua franca during encounters between those international students and faculty members and between them and Chinese students.

Data reported in this paper were retrieved from an on-line questionnaire survey which was administered in Chinese (see Appendix A for its English version). This survey, the very preliminary step of the whole project, intends to uncover how participants perceive different English accents and how different accent perceptions relate to their identities. It consists of 29 close-ended questions (including 2 rank ordering open-ended questions) and 2 open-ended questions. Specifically, it was divided into four major parts, with each part targeting a specific theme. In particular, the first part (from Q1 to Q6) which is adapted from Norton (2000), is meant to elicit the respondent's biographical profile, which also serves as independent variables in statistic tests. The second part (from Q7 to Q14) adapted mainly from Fang (2015) is designed to elicit their understandings of and attitudes toward different English accents (including English accents of their own). The third part (from Q15 to Q31) is further divided into two subcategories, in which Q15 to Q22 also adapted from Fang (2015) address the issue of accent inclination, and Q23 to Q30 which were adapted from Jenkins (2000) address accent acceptance scales. It is ended with Q31, an open-ended question eliciting comments on the survey per se or participants' understandings related to English accent.

To counter the greatest challenge, low response rate in questionnaire survey, the researcher turned most of the survey items (except Q5 and Q31) into compulsory questions. This means that respondents were unable to submit their questionnaires unless they completed all compulsory questions; secondly, the researcher also sought an opportunity to introduce the necessary essentials of the research project to the participants prior to the formal commencement of the research. Participants were advised to fill in the survey wherever and whenever they felt most convenient thanks to the respondent-friendly nature of e-survey platform within a one-month time limit.

The retrieved raw data were then firstly translated from the participants' mother tongue, Chinese, to the target language, English, which was followed by data screening and data cleaning so as to spot and correct errors and inaccuracies. Consequently, the data, after necessary elimination, were reduced from 599 to 574 valid questionnaires. In addition, participants' responses to Q5, Q7 and Q12 were reduced (see Appendix B) to a much more manageable size while maintaining original information. Besides research ethics and integrity were always major concerns of this study. The researcher has obtained ethical approval (Ref. No.: UM.TNC2/UMREC-249) from her affiliation prior to the start of the research. 


\section{DATA ANALYSIS}

Both descriptive statistics and inferential statistics were adopted with the assistance of SPSS 20.0 in accordance with the research purposes and the categories of the retrieved data. The basic demographic information of the participants is displayed in Appendix C. Briefly, the majority of the participants $(\mathrm{N}=391)$ fell in the 16 to 20 year age group (accounting for $68.1 \%$ ), and were skewed to the female side $(87.8 \%)$ which is analogous to the typical features of English major students in China, that is the enrollment of female students is usually several times more than that of male students. The number of first $(\mathrm{N}=162)$ and second year participants $(\mathrm{N}=167)$ were slightly more than third $(\mathrm{N}=132)$ and fourth year participants $(\mathrm{N}=113)$, and a considerable number of them (63.2\%) began their English study from primary schools. In addition, there were way less participants with any overseas experiences $(\mathrm{N}=37)$ than participants without overseas experiences $(\mathrm{N}=537)$.

Qualitative data refers to responses to the open-ended questions, Q11, a compulsory item, and Q31, an optional question, in the questionnaire. Qualitative data were firstly translated from Chinese to English and then coded into different categories and analysed with the assistance of Nvivo 11.0.

\section{RESULTS AND DISCUSSION}

Responses were combined and centered around three major themes: attitudes toward English accents and pronunciation teaching, accent inclination, and accent acceptance. In what follows efforts were made to report the relevant results in thematic units and possible interpretations were accordingly provided by the researcher.

\section{ATTITUDES TOWARD ENGLISH ACCENTS AND PRONUNCIATION TEACHING}

The first thematic group can be further divided into four subcategories: attitudes toward English accents that respondents are most familiar with, respondents most prefer and respondents most aspire to have; English accent evaluation; attitudes toward respondents' own English accent and beliefs in pronunciation teaching.

\section{ENGLISH ACCENTS RESPONDENTS ARE MOST FAMILIAR, MOST PREFER AND MOST ASPIRE TO HAVE}

Figures 1 to 3 display responses to Q7, Q12 and Q13, that is, different English accents that respondents were most familiar, most preferred and most aspired to. In each case, similar to most findings, NES, in particular, British English accent and American English accent were still perceived as the top two most familiar and the most preferred and aspired English accents, the combination of which in each case claims nearly 90 percent of the total population of the respondents. 


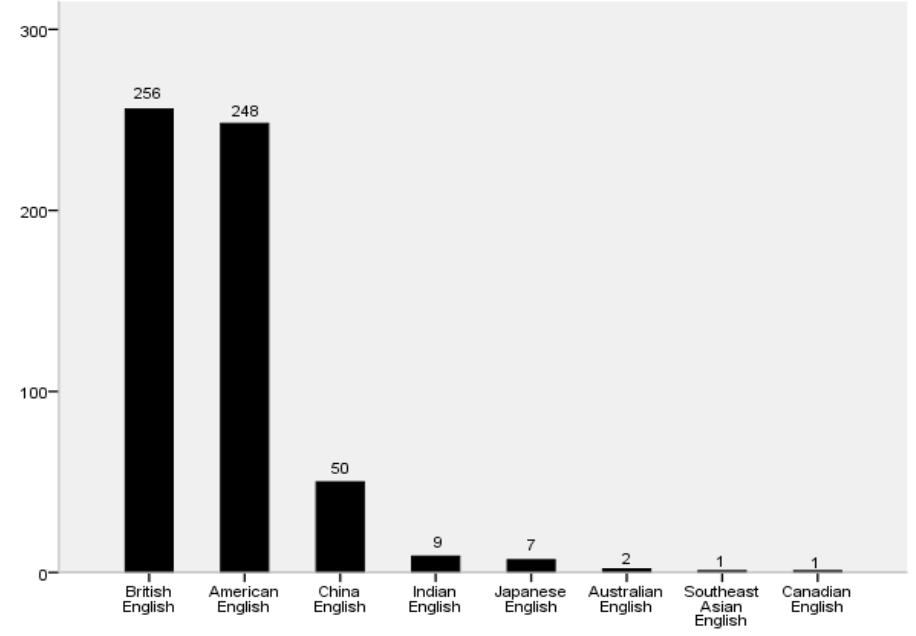

FIGURE 1. English Accents Respondents Most Familiar

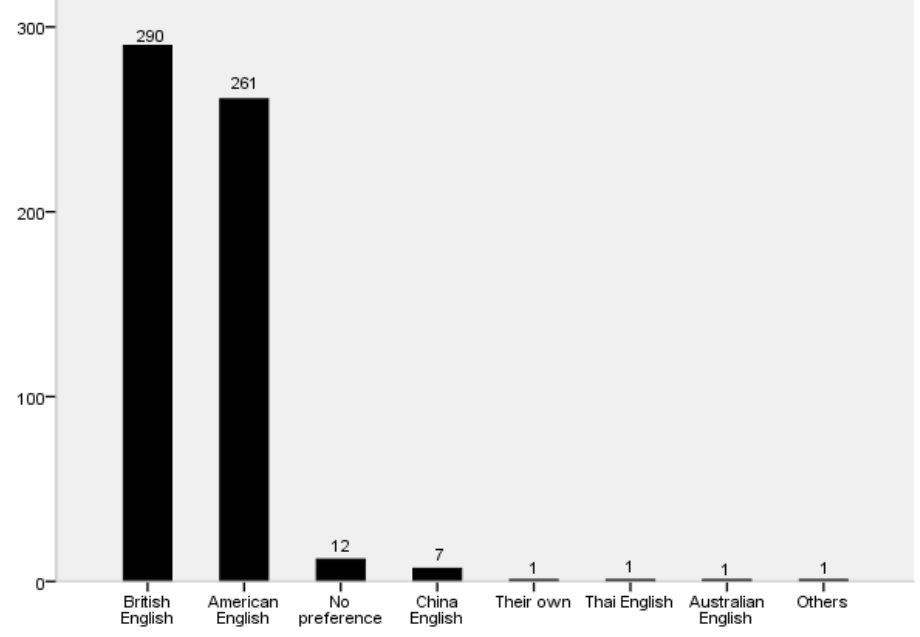

FIGURE 2. English Accent Respondents Most Prefer

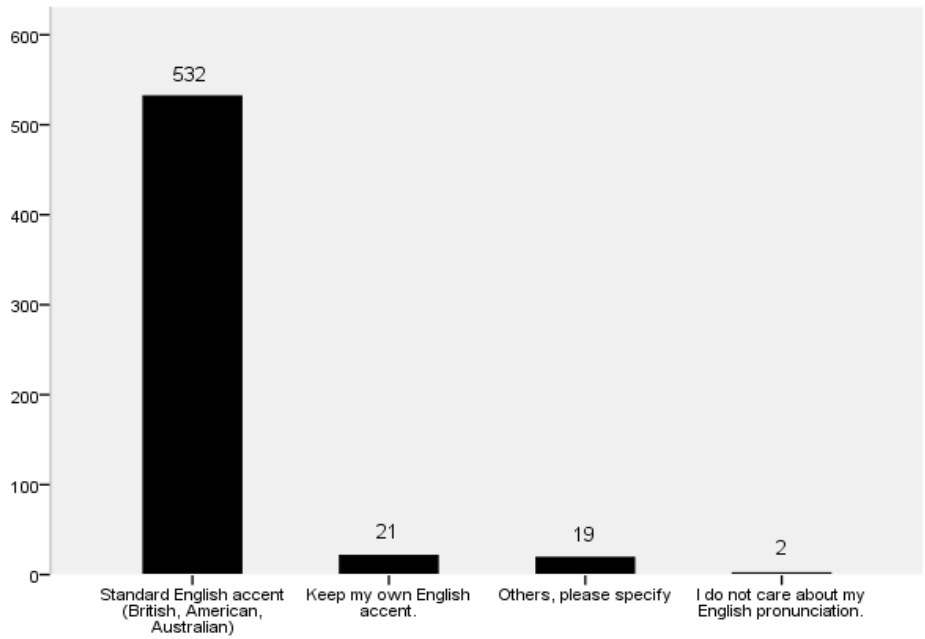

FIGURE 3. English Accents Respondents Most Aspire to Have

The unswervingly dominant position assumed by NES accents, in particular, British and American English accents found in this survey, is comparable to a group of findings (c.f. Fang, 2015; He \& Li, 2009; He \& Zhang, 2010; Hu, 2004; Jenkins, 2007, 2009; Sa'd \& 
Modirkhameneh, 2015; Sung, 2016; Y. Wang, 2012), and it came as no surprise and can be accounted for by the following interpretations. First and foremost, a majority of the respondents in this survey albeit their common identity as language learners, confessed honestly that they were ignorant of other English accents apart from the top two "Standard English accents" which as revealed in their open comments were stipulated by their English teachers or syllabuses as the default point of references ever since their first contact of English study. Even if some of them were exposed to other English accents, the most possible scenario for them was either to regard the other different English accents, such as the mentioning of Indian English, Japanese English, and Pakistani English by the respondents in Q31, as negative examples to further boost their beliefs in the pursuit of NES accents, or to treat them as cases of exceptions which from the respondents' perspectives were unlikely to be encountered in the future. Their perception is understandable given that no one made this endeavor to inform them of the fact that the population of NNES has outnumbered NES population for long against the backdrop of SLA-ideology-prevalent ELT in China, which corroborates Wang's (2012) suggestion that the knowledge of English globalization should be popularised in China.

Another possible interpretation of this trend points to factors beyond language. That Britain introduced English to the entire world through its military prowess during colonial period, and America successively facilitated the global permeation of English in post-colonial era via its economic, political, cultural and technological capabilities (Phillipson, 1992) came as unquestionable justifications for its dominant position over other NNES English varieties on the part of the respondents. Evidences such as "Britain is the birth place of English.", "My ears are pregnant listening to Americans speaking English.", "The ultimate purpose for me to study English is to go to America to experience its culture." etc. were found recurrent in the respondents' open comments. The last but not the least important justification is because of the influence of technology-based mass-media. English is no longer an academic subject to the respondents but highly accessible in their daily life, thinking about the entertainment industry, the skyrocketing number of imported Hollywood blockbusters, American and British TV and radio programmes into Chinese market. The most likely outcome is captured fully by a respondent's comment,

S392: My most favourite leisure time activities are listening to American pop music, and watching mostly American TV dramas. I really enjoy the plots and the characters, and I would intentionally imitate their accent, their way of speaking English and even their body gestures.

But what is new and inspiring in the findings, after close examination of the three bar charts, are the following three additional points. Firstly, the top two English accents, i.e. British English accent and American English accent, were still the most exposed English accents in the case of the respondents. However, there seems a growing trend of exposures to a wider range of different English accents, such as China English accent $(\mathrm{N}=50)$, Indian English accent $(\mathrm{N}=9)$, Japanese English accent $(\mathrm{N}=7)$, Australian English accent $(\mathrm{N}=2)$, Canadian English accent and Southeast English accent ( $\mathrm{N}=1$ respectively), which albeit the small percentage indicated a growing language awareness on the part of the respondents in the wake of frequent contacts with other English varieties (Seidlhofer, 2002, 2011). It is also a question of interest if any ensuing exposure to different NNES accents would substantially change the way they perceive NES accents, which is to be tested within the domain of upcoming qualitative research.

Secondly, 551 (96\%) respondents expressed preference for either British English accent or American English accent; in other words, 23 respondents held other preferences, which were supplemented by their open comments in Q31. For example, some respondents made the following remarks: 
S27: For English accents, I personally think that the first requirement is to be able to express clearly and fluently and being standard comes second.

S544: When I learned English from primary school, I was exposed to British and American English accents. When I arrived at the university, I also met a variety of accented Englishes, and I felt that it doesn't matter. I may not understand it at first, but after I got used to it, understanding is not a problem. So I don't think accent should be a reason for not being able to understand.

Themes that can be instilled from the comments above are pragmaticity, clarity, intelligibility, fluency and familiarity, which kept recurring sometimes independently, sometimes along with the endorsement given to either of the top two most preferred English accents in the respondents' comments. It indicates either ambivalence of attitudes toward standard English accents (c.f. Jenkins, 2005) or questioning of the unquestionable status accorded to standard English accents on the part of the respondents, which becomes even more evident when it comes to evaluate their own English accents.

Thirdly, there was a moderate drop in the number of respondents who aspired to standard English accents in comparison with the combined number of respondents who claimed preference to British and American English accents. To be specific, 21 of them chose to maintain their own English accents, but it is worth taking note of the particular features of the respondents' own English accents that have actually led to such a decision. Another 19 of them opted for other English accents, which were specified in addition as follows:

\section{S373: As long as people in other English-speaking countries or people speaking English can understand my meaning, it is not necessary to obtain a standard English accent. \\ S432: I'd like to retain some of my own cultural characteristics on the basis of the standard English accent when speaking in English.}

In brief, responses to Q7, Q12 and Q13 display an obvious bias in familiarity, preference and aspiration to standard English accents, in particular, British and American English accents. What's noticeable in the meantime is the growing number of English varieties the respondents exposed to, and other options besides standard English accents the respondents preferred and aspired to have.

\section{EVALUATION OF ENGLISH ACCENTS}

Findings from Q8 and Q9 were comparable to that of Jenkins' (2007) and Fang's (2015). Though less respondents $(\mathrm{N}=221,38.5 \%)$ approved of the claim that some English accents are more prestigious than others (Q8), more than half of them $(\mathrm{N}=317,55.2 \%)$ held the belief that some English accents are easier to understand (Q9) (See Table 1 and 2).

TABLE 1. Whether some English accents are more prestigious than others?

\begin{tabular}{llccc}
\hline & & Frequency & Percent & Valid Percent \\
\hline \multirow{4}{*}{ Valid } & No. & 221 & 38.5 & 38.5 \\
& No idea. & 177 & 30.8 & 30.8 \\
& Yes. & 176 & 30.7 & 30.7 \\
& Total & 574 & 100.0 & 100.0 \\
\hline
\end{tabular}

TABLE 2. Whether some English accents are easier to understand?

\begin{tabular}{llccc}
\hline & & Frequency & Percent & Valid Percent \\
\hline \multirow{4}{*}{ Valid } & No. & 90 & 15.7 & 15.7 \\
& No idea. & 167 & 29.1 & 29.1 \\
& Yes. & 317 & 55.2 & 55.2 \\
& Total & 574 & 100.0 & 100.0 \\
\hline
\end{tabular}


Justifications were provided along with the "Yes/No" options. Primary reasons underneath their perception that some English accents are not more prestigious than others $(\mathrm{N}=221)$ were explicated in the following remarks, with key words or phrases underlined:

S20: The preference for different English accents is rather personal, and there's nothing to do with superiority.

S42: The purpose of language learning is for the sake of mutual communication and mutual understanding. As long as my thoughts and expressions can clearly reach the other party, my English accent is a good English accent.

S124: English accent itself does not have superiority, but people who speak with it have.

S155: I think different English accents are caused by different culture and geographical locations. An accent has a unique taste in that area, and there is no hierarchy existing in them.

In comparison, justifications provided to support the claim that some Englishaccents are more prestigious than others $(\mathrm{N}=176)$ were mostly expressed in phrases, recurrent ones such as "sounds comfortable", "sounds formal and official", "more elegant", "more clear and intelligible", "pure and authentic", "standard", "international and efficient". A number of complete explanations facilitate clarifying their inclination, for example,

\footnotetext{
S78: Authentic English accent is better than accented Englishes, and English with accents will be laughed at by others.

S186: Standard English accent will reflect a person's identity, knowledge and education, and it will make the listener hear clearly and comfortably.

S201: The current English textbooks are biased towards British English accent, so does the audio pronunciation heard during the exams, which means my perception is influenced by the current environment.
}

Reasons retrieved from the respondents' further comments on whether some English accents are easier to understand than others (Q10) were interestingly corresponding, that is, reasons for the respondents to vote against the claim are the very reasons for them to vote for it, for example,

S157: The expressed content is the same, it is not which one is easier to understand, but which one is more familiar, then that one is easier to understand.

The latter part of the comment became the major reason for their support of the claim,

S47: The most recognised English accents in the world today are British and American English accents...Together with the cultural output of the United Kingdom and the United States, these two accents became the most often-heard English accents, and undoubtedly, they became the most familiar English accents compared with others, so they are easier to understand.

What should not be neglected in the two tables are the significant numbers of respondents $(\mathrm{N}=176,167$ respectively) who answered "No idea". The first justification of their option is due to the plain fact that a considerable number of them, especially the first graders, had no such exposures to different varieties of English accents and British and American English accents are their only accessible sources of English varieties. Another possible interpretation, in line with comments provided in Q31, is that they did not care about which English accent they took so long as they could manage smooth conversations with people involved.

Chi-square tests were conducted to investigate whether age, gender, grade, duration of English learning and experiences abroad exerted any impact on the way the respondents evaluated different English accents, in which age and gender were found to have statistically 
significant impact on how they responded Q8, $\mathrm{p}=0.029,0.038$, albeit the effect size was rather small, phi $=0.111,0.107$ respectively. Grade, for another, was tested significantly related to responses to $\mathrm{Q} 9, \mathrm{p}=0.018$, also with minor effect size given $\mathrm{phi}=0.100$.

In brief, despite the fact that NES accents, in particular, American and British English accents were on the top of the pyramid, they were not the default answers when it comes to superiority, which indicates that the respondents were more likely to identify with language for language's sake, and which for another corroborates Jenkins' (2007) finding that L2 learners might desire NES but not NES-like identity.

\section{ATTITUDES TOWARD RESPONDENTS' OWN ENGLISH ACCENTS}

Respondents in Q10 were expected to describe their own English accents, and in Q11 to evaluate their own English accents against 5 point-rating scales. Responses to Q11 were displayed in Table 3 which shows a centralized tendency $(\mathrm{SD}=0.909)$ on the part of the respondents in providing generally a statistically negative evaluation (mean $=2.72$, minimum $=1$, maximum=5) of their own English accents.

TABLE 3. How do you feel about your own English accent?

\begin{tabular}{llccc}
\hline & Frequency & Percent & Valid Percent \\
\hline \multirow{4}{*}{ Valid } & Not satisfied at all & 27 & 4.7 & 4.7 \\
& Not very satisfied & 250 & 43.6 & 43.6 \\
& Uncertain & 159 & 27.7 & 27.7 \\
& Satisfied & 131 & 22.8 & 22.8 \\
& Very satisfied & 7 & 1.2 & 1.2 \\
& Total & 574 & 100.0 & 100.0 \\
\hline
\end{tabular}

Specifically, close to one half $(48.3 \%)$ of the respondents were not satisfied with their own English accents. In contrast, less than a quarter (24\%) of them felt satisfied with their current English accents; while the rest, more than a quarter $(27.7 \%)$ did not provide clear evaluation in terms of their own English accents and chose "Uncertain".

Comments retrieved by Q10, a compulsory open-ended question, provided fresh clarifications for the above-observed statistical trend. "Accent" (mentioned 263 times out of 574 responses), "English" (194 times), "standard" (152 times), "Chinese" (139 times) and "mixed" (74 times) were the top five words with the highest frequencies running exact matches via Nvivo 11.0. Follow-up enquiries discovered that more than one third of the respondents described their own English accents as with "Chinese English accent", which in most cases was held negatively by the respondents as an indicator of failed English language learners; responses relevant to "standard" were mostly expressed in a negative way, such as "not standard", "not quite standard", or "not standard at all"; responses related to "mixed" were also interesting in that it either indicated a mix of British and American English accents or a mix of British, American and Chinese English accents. Even if in random cases that some respondents expressed satisfaction with their own English accents, they would in the meantime add that they would strive to sound as close as possible like a NES, which indicates a sense of ambivalence and inferiority in attitude or an identity conflict experienced by some respondents. On the one hand they were eager to project their "Ought-to" Self by identifying with their own current English accents; on the other they were tormented by their "Ideal" Self which forced them to identify with NES accents (Dörnyei, 2009; Ushioda \& Dörnyei, 2009).

It is not difficult to come up with a sound justification for this rather negative and contradictory evaluation of their own English accents on the part of the respondents. As Zheng (2013) observed that most students in China still label themselves as "perennial and error-prone ENL learners" other than rightful English language users, not surprisingly NES accent models are regarded as their ultimate goals of their endeavors and their default reference points albeit 
"unrealistic and unattainable in their locale" (Ibid.). In other words, English in this case was still perceived as a foreign language by a considerable majority of the respondents, though it is against the fact that English for now has been widely employed as an auxiliary language, a lingua franca, possessing regional characteristics and emotive values (Hashim, Kaur \& Kuang, 2016), and it also blindfolds the emerging ELF reality at the research site where a growing proportion of communications by means of English were conducted between NNESs in the absence of NESs. In view of this, it is no wonder that the respondents' mother tongue was perceived as a negative transfer impeding their progress as successful foreign language (FL) learners.

Chi-square tests were conducted but it was found that there was no significant impact exerted by the independent variables on the way the respondents perceived their own English accents. But interestingly descriptive statistics show that a difference exists between respondents with and without overseas experiences, in which respondents with overseas experiences tend to hold more favorable opinions on their own English accents (mean=3.38) than respondents without overseas experiences (mean=2.68). An independent t-test was therefore conducted and found that it was statistically different between students with and without overseas experiences in how they evaluated their own English accents, $\mathrm{F}=1.065$, $\mathrm{p}=0.000$, and the effect size, given Cohen's $\mathrm{d}=0.825$, is large. In similar vein, a one-way ANOVA reported a significant difference among respondents in different grades in the way they evaluate their own English accent, $\mathrm{F}=4.593, \mathrm{p}=0.003$, but with a small effect size $(\mathrm{f}=0.147)$. What is indicated in this finding is comparable to Chiba et al.'s (1995) and Dewaele and McCloskey's (2015), in that when the respondents had more exposure to different varieties or variations of English, they tended to have positive views of NNES accents, including accents of their own.

In brief, Q10 and Q11 report a generally negative trend in the way the respondents perceived their own English accents. NES accents were the benchmark for their evaluation of their own English accents and their L1 influenced-English accents were treated pejoratively and were on top of the list to be ridded off. This evaluation was independent of the effect of age, gender, grade, duration of English study and overseas experiences, albeit statistical differences exist between respondents with and without experiences abroad, and among respondents in different grades.

\section{BELIEFS IN PRONUNCIATION TEACHING}

Q14 was designed as a multiple-choice question which means that the respondents were permitted to tick more than one option as long as they thought the option they ticked was reasonable and acceptable. Q14 thus became the only item in this survey that the number of the ticked options was larger than the number of the respondents (see TABLE 4). Note that percentage and valid percentage were calculated against the total population of the respondents other than the total number of the ticked options.

TABLE 4. English accent(s) teachers should teach

\begin{tabular}{lcccc}
\hline \multicolumn{1}{c}{ English accents teachers should teach } & Frequency & Percent & Valid percent \\
\hline \multirow{4}{*}{ V A } & 545 & 94.9 & 94.9 \\
& B & 50 & 8.7 & 8.7 \\
C & 47 & 8.2 & 8.2 \\
D & 32 & 5.6 & 5.6 \\
E & 10 & 1.7 & 1.7 \\
\cline { 2 - 4 } A. Standard English accent (British, American, Australian) & & 684 & \\
B. China English accent & & & \\
C. The English accent(s) the teacher is familiar with & & & \\
D. A mix of native and non-native English accent & & & \\
E. Others, please specify & & & \\
\hline
\end{tabular}


Out of 684 overall options retrieved from the respondents, 545 respondents chose standard English accent as the most satisfactory pronunciation model teachers were supposed to teach students, which is in line with the previous findings in this survey study, and which is for another revealing the strong conformity to standards and correctness stemming from the Chinese administrative level (c.f. He \& Zhang, 2010; Kirkpatrick \& Xu, 2002; W. Wang, 2015; Y. Zheng, 2013). For another, however, 139 options were dedicated to other English accent models, which once again indicates a growing language awareness and emerging questioning of dogged adherence to standard English norms on the part of the respondents. Correlation tests were conducted and there seemed no effect of the independent variables on the choices of different English accent models to be taught made by the respondents.

In brief, NES or standard English accent maintains its momentum as the most preferred English accent models to be taught from the perspectives of the respondents. Noticeable also is attention received by other English accent models, such as China English accent. Inferential statistic tests found that there was no relation between the independent variables and the respondents' preferred pronunciation models.

\section{ACCENT INCLINATION}

Question items (Q15 to Q22) in this part were intended to retrieve responses in how the respondents identified themselves with different accent situations. The preliminary descriptive statistics in reference to their different accent inclination was captured in the following table.

TABLE 5. Accent inclination

\begin{tabular}{lcc}
\hline \multicolumn{1}{c}{ Statements } & Mean & SD \\
\hline Q15: I feel happy when I find my English accent is more like native speakers. & 5.25 & 1.079 \\
Q16: When someone cannot understand me when I speak English, I begin to doubt my & 4.06 & 1.472 \\
English accent. & 2.99 & 1.267 \\
Q17: I feel satisfied with my English accent as well as my Chinese accent. & 4.30 & 1.308 \\
Q18: I do not feel satisfied with my English accent and would strive to sound like a & 4.04 & 1.451 \\
native speaker of English. & 2.96 & 1.310 \\
Q19: I feel satisfied with my own English accent but would still like to strive to sound & 4.97 & 1.254 \\
like a native speaker of English. & 2.51 & 1.207 \\
Q20: I feel satisfied with my own English accent and would like to keep it. & & \\
Q21: I feel happy if someone mistakenly regards that I have a native speaker accent of & & \\
English. & &
\end{tabular}

What can be obtained from the preliminary investigation is as follows: Q15 has the highest mean score (5.25) and the lowest SD value (1.079); in contrast, Q22 has the lowest mean score (2.51). More interestingly, statements centered around maintaining their own English accent were unexceptionally obtained lower means, with an overall average mean score (Q17, Q20, Q22) as 2.82, an overall average SD 1.26; contrastingly, statements revolved around changing their own English accents so as to approach native English speakers, with the only exception Q16 which will be explicated later in detail, obtained much higher mean scores, with an overall average mean score 4.52, and SD 1.31.

The results indicated that most respondents felt very much reluctant to project their Chinese identity via Chinese-accented English, and they were in other words experiencing a "subtractive identity change" (Gao et al., 2005; 2007). Additionally, Q16 in Gao et al.'s (2005; 2007) exploratory research, was categorised as related to self-confidence change which means changes in how the respondents perceive their own competence, and is essentially independent of "cultural identities". The comparatively high mean score (4.06) and the moderate SD value (1.472) suggest that a noticeable number of respondents agreed that their self-confidence was correlated positively with their English accent. Q18 and Q19 for another indicate "split change" 
in Gao et al.'s $(2005 ; 2007)$ term which indicates an identity conflict brought by "struggle between languages and cultures", which is further evidenced in the respondents' open comments,

S328: I think my English is of Chinese accent, and I don't feel uncomfortable with it, but I still want to say smooth English like a native speaker.

Split change is treated as an "intermediate phase" before learners "develop other types of identity changes" (Gao et al., 2005; 2007). High mean scores retrieved from the two items indicate that a proportion of the respondents underwent an obvious split change which would eventually lead them to other identity changes.

Chi-square tests were conducted to investigate the possible factors influencing respondents' accent inclination. Age, gender, grade, duration of English study and experiences abroad were tested of having no statistically significant impact on accent inclination. Additionally, no significant differences were found between gender, different age groups, with or without overseas experiences, or among different grades or different duration of English study.

In brief, respondents were inclined to hold negative perspectives to statements which give positive description of their own English accent but positive feedbacks to statements which encourage them to modify their own English accent in reference to native English speakers. There is reluctance on the part of the respondents in projecting their Chinese identity in speaking English and their self-confidence was tested to be correlated positively with their English accent. No significant inferential statistics has so far been obtained at this stage.

\section{ACCENT ACCEPTANCE}

Question items in this part incorporated a number of well-attested items, such as Q23, Q26, Q27 and Q30, were adapted from Jenkins' (2000). Those items refer to cases that were proved to be of having no significant hindrance in successful communication. Other question items were designed in line with pronunciation features exclusive to Chinese English learners (Chang, 1987; Zhang \& Zhao, 2014). The purpose of the inclusion of this part is to test to what extent the respondents were willing to give their endorsement to those deviant forms of English pronunciations. Table 6 captures the discrete mean scores and SD values of each item, and Table 7 displays the overall statistic results.

TABLE 6. Accent acceptance

\begin{tabular}{lcc}
\hline & Mean & SD \\
\hline Q23: "think"read as //ink/ or /sink/ & 2.67 & 1.464 \\
Q24: "live"read as /li:v/ & 4.20 & 1.460 \\
Q25: "nice"read as /lais/ & 2.66 & 1.624 \\
Q26: "red paint" read as /reb peInt/ & 2.51 & 1.549 \\
Q27: "these"read as /di:z/ & 1.81 & 1.189 \\
Q28: "vegetable"read as /"wedztəbəl/ & 2.92 & 1.559 \\
Q29: "product"read as /"ppdAk/ & 2.60 & 1.495 \\
Q30: "command"read as /kə' ma:nde/ & 3.06 & 1.509 \\
\hline
\end{tabular}

TABLE 7. Overall accent acceptance

\begin{tabular}{cccccc}
\hline & N & Min & Max & Mean & SD \\
\hline $\begin{array}{c}\text { Accent acceptance } \\
\text { Valid N }\end{array}$ & 574 & 1 & 6 & 2.805 & .959 \\
\hline
\end{tabular}

Findings from this part rendered the most interesting results and were found in stark contrast to that of Jenkins'(2000, 2002). If interpreting from a general level, the overall mean 
score for deviant accent acceptance is low (mean=2.805), and it is agreed upon by a majority of the respondents $(\mathrm{SD}=0.959)$. Discretely, $\mathrm{Q} 27$, whose way of pronunciation is so widespread that it has been long attested to of rendering no difficulty or hindrance in conversations, receives the lowest mean score as well as the lowest SD value. This means that a considerable number of the respondents would have paramount difficulty as listeners once encountering people with such accent and the possibilities of bringing the conversation to a breakdown are high as they as listeners fail to accomplish their due part (Smith, 1992), which is further evidenced in their Q31 open comments,

\section{S42: Whenever I communicated with Pakistani students, I couldn't understand them. Their local accent was too strong, and their pronunciation was not authentic, which made me very upset. S184: ... There was once a Polish oral English teacher who made me really uncomfortable when in his class. I couldn't figure out what he was talking about, and felt that his English was so much different from what I learnt....}

Surprisingly, the unexpectedly high mean score (mean=4.20) received by Q24 indicates that considering the moderate $\mathrm{SD}$ value $(\mathrm{SD}=1.460)$, a noticeable portion of the respondents downplayed the significance of the maintenance of contrast between long and short vowels (Jenkins, 2000) which was stipulated clearly about the possible conversation breakdowns if violated.

To further investigate possible effect exerted by the independent variables, Chi-square tests were again conducted but with no statistically significant results being found. Nevertheless, significant difference was found in different age groups in how they accepted accents deviant from standard versions, $\mathrm{F}=0.088, \mathrm{p}=0.004$, but with rather small effect size, given Cohen's $d=0.261$. Statistically significant difference was also observed among different grades, $\mathrm{F}=10.572, \mathrm{p}=0.000$, but with moderate effect size, $\mathrm{f}=0.228$.

In brief, the respondents tended to hold negative perceptions toward the deviant forms of English pronunciations, including a number of well-attested forms of pronunciation rendering no extra difficulty in understanding. Some provisional interpretations are therefore considered, such as loopholes existing in pronunciation teaching in China. In specific, one possible interpretation is that English language instructors failed to expose language learners to the English language reality happening around the world, which risks Chinese English language learners failing to accomplish successful conversations. Another likely interpretation is that English language instructors failed to underline the core phonetic symbols which guarantee successful conversations and prevent communication breakdowns.

\section{CONCLUSION}

The questionnaire survey, an initial phase of a longitudinal research, reports at a preliminary level different attitudes toward different English accents and to what extent accents intersect with identities on the part of the Chinese tertiary-level English language learners. The current study reports an obvious bias towards NES or standard English accents, in particular, British and American English accents, which assumed the roles as the most familiar, the most preferred, and the most aspired and also as the default point of reference. On the other hand, there exists a strong bias against Chinese-accented English and other NNES accents on the part of the respondents who felt reluctant to project their Chinese identity by means of Chinese-accented English which for them is as an unwelcoming marker of being failed language learners against the framework of SLA.

Contrastingly, there also seems in this survey an emergence of linguistic rights and learner identity experienced by some respondents albeit the number is comparatively small, which demonstrates itself in highlighting communicative pragmaticity, endorsing L1 Chinese 
identity, and questioning benchmark roles accorded to NES accent standards. Another significant finding is the respondents' overseas experiences, i.e. respondents with overseas experiences are more likely to evaluate their own English accents favourably in comparison with respondents without overseas experiences, which indicates potential perception changes on the part of the respondents in line with the accumulation of contacts with different English varieties.

Possible factors that accounted for the respondents' attitudinal differences were also addressed. One major factor among others is the way that English is being perceived, i.e. it has still been treated by most respondents as a foreign language despite the fact that internationally and domestically an increasing number of communications are being conducted between NNESs without the presence of NESs. Their propensity of setting NES accent norms as their default benchmark and of labelling themselves as "perennial English learners" thus come as no surprise. But it remains open if their perceptions toward different English accents will change in the course of time responding to the increasing exposure to different English varieties, so do their identities, which is unable to be fully captured by this one-off questionnaire survey.

The pedagogical implications obtained from this survey study are significant in that it poses a series of questions, such as how to address the controversies between the linguistic reality and the prescriptive standards, between the respondents' hidden appeals for an enhancement of their pragmatic competence (Li, Raja, \& Sazalie, 2015) and for projecting their identity via L1-accented English and highly-acclaimed NES accent models. That whether these conflicts would be resolved against the framework of SLA or ELF, which becomes an issue of special prominence in China due to its monolingual and standard-advocated reality (Jenkins, 2000), remains to be tested by further research.

\section{REFERENCES}

Allport, G. W. \& Cantril, H. (1934). Judging personality from voice. The Journal of Social Psychology. 5(1), 37-55.

Bian, Y. (2009). Chinese Learners Identity in Their Attitudes towards English Accents. CELEA Journal. 32(2), 66-74.

Chang, J. (1987). Chinese Speakers. In M. Swan \& B. Smith (Eds.), Learner English: A Teacher's Guide to Interference and Other Problems (pp. 310-324). Cambridge: Cambridge University Press.

Chiba, R., Matsuura, H. \& Yamamoto, A. (1995). Japanese attitudes toward English accents. World Englishes. 14(1), 77-86.

Chihara, T. \& Oller, J. (1978). Attitudes and attained proficiency in EFL: A sociolinguistic study of adult Japanese speakers. Language learning, 28(1), 55-68.

Dalton, C. \& Seidlhofer, B. (1994). Pronunciation. Oxford: Oxford University Press.

Dalton, C., Puffer, C., Kaltenboeck, G., \& Smit, U. (1997). Learner attitudes and L2 pronunciation in Austria. World Englishes, 16(1), 115-128.

Dewaele, J.-M. \& McCloskey, J. (2015). Attitudes towards foreign accents among adult multilingual language users. Journal of Multilingual and Multicultural Development. $36(3), 221-238$.

Dörnyei, Z. (2009). The L2 Motivational Self System. In Z. Dörnyei \& E. Ushioda (Eds.), Motivation, language identity and the L2 self (pp. 9-42): Multilingual Matters.

El-Dash, L. G. \& Busnardo, J. (2001). Brazilian attitudes toward English: Dimensions of status and solidarity. International Journal of Applied Linguistics. 11(1), 57-74.

Fang, F. (2015). An investigation of attitudes toward accent at a Chinese university. (Doctor of Philosophy), University of Southampton.

Gao, Y. (2014). Faithful imitator, legitimate speaker, playful creator and dialogical 
communicator: shift in English learners' identity prototypes. Language and Intercultural Communication. 14(1), 59-75.

Gao, Y., Cheng, Y., Zhao, Y., \& Zhou, Y. (2005). Self-identity Changes and English Learning among Chinese Undergraduates. World Englishes. 24(1), 39-51.

Gao, Y., Zhao, Y., Cheng, Y., \& Zhou,Y. (2007). Relationship between English learning motivation types and self - identity changes among Chinese students. Tesol Quarterly. 41(1), 133-155. Garrett, P. (2010). Attitudes to language: Cambridge University Press.

Graddol, D. (2006). English Next: Why Global English May Mean the End of 'English as a Foreign Language'. London: British Council.

Hansen Edwards, J. G., Zampini, M. L. \& Cunningham, C. (2019). Listener judgments of speaker and speech traits of varieties of Asian English. Journal of Multilingual and Multicultural Development. 40(8), 691-706.

Hashim, A., Kaur, J. \& Kuang, T. S. (2016). Identity regionalism and English as an ASEAN lingua franca. Journal of English as a Lingua Franca. 5(2), 229-247.

He, D. (2015). University students' and teachers' perceptions of China English and world Englishes: Language attitudes and pedagogic implications. The Asian Journal of Applied Linguistics. 2(2), 65-76.

He, D. \& Li, D. C. S. (2009). Language attitudes and linguistic features in the 'China English' debate. World Englishes. 28(1), 70-89.

He, D. \& Zhang, Q. (2010). Native Speaker Norms and China English: From the Perspective of Learners and Teachers in China. Tesol Quarterly. 44(4), 769-789.

$\mathrm{Hu}, \mathrm{X}$. (2004). Why China English should stand alongside British, American, and the other 'world Englishes'. English Today. 20(2), 26-33.

Jenkins, J. (2000). The Phonology of English as an International Language. Oxford University Press.

Jenkins, J. (2002). A sociolinguistically based, empirically researched pronunciation syllabus for English as an international language. Applied linguistics. 23(1), 83-103.

Jenkins, J. (2005). Implementing an International Approach to English Pronunciation: The Role of Teacher Attitudes and Identity. Tesol Quarterly. 39(3), 535-543.

Jenkins, J. (2007). English as a Lingua Franca: Attitude and Identity English as a Lingua Franca: Attitude and Identity. Oxford University Press.

Jenkins, J. (2009). (Un)pleasant? (In)correct? (Un)intelligible? ELF Speakers' Perceptions of Their Accents. In A. Mauranen \& E. Ranta (Eds.), English as a lingua franca: Studies and findings. Newcastle: Cambridge Scholars Publishing.

Jiang, Y. \& Du, R. (2003). Issues on "China English". Foreign Language Education, 24, 27-35.

Kirkpatrick, A. \& Xu, Z. (2002). Chinese pragmatic norms and 'China English'. World Englishes. 21(2), 269-279.

Lambert, W. E., Hodgson, R. C., Gardner, R. C. \& Fillenbaum, S. (1960). Evaluational reactions to spoken languages. The Journal of Abnormal and Social Psychology. 60(1), 44-51.

Li, R., Raja, R. \& Sazalie, A. (2015). An Investigation into Chinese EFL Learners' Pragmatic Competence. GEMA Online ${ }^{\circledR}$ Journal of Language Studies. 15(2), 101-118.

Lindemann, S., Litzenberg, J. \& Subtirelu, N. (2014). Problematizing the dependence on L1 norms in pronunciation teaching: Attitudes toward second-language accents. In J. Levis \& A. Moyer (Eds.), Social dynamics in second language accent (pp. 171-194). Mouton: De Gruyter.

Lippi-Green, R. (1994). Accent, standard language ideology, and discriminatory pretext in the courts. Language in society. 23(2), 163-198.

Lippi-Green, R. (1997). English with an accent: Language, ideology, and discrimination in the United States. Psychology Press. 
Luk, J. C. \& Lin, A. M. (2006). Uncovering the sociopolitical situatedness of accents in the World Englishes paradigm Spoken English, TESOL and applied linguistics (pp. 3-22): Springer.

Norton, B. (2000). Identity and Language Learning: Gender, Ethnicity and Educational Change. Harlow, England; New York: Longman.

Oller, J., Hudson, A. J. \& Liu, P. F. (1977). Attitudes and attained proficiency in ESL: A sociolinguistic study of native speakers of Chinese in the United States. Language learning. 27(1), 1-23.

Pear, T. H. (1931). Voice and Personality. London: Chapman and Hall Ltd.

Phillipson, R. (1992). Linguistic imperialism. Oxford: Oxford University Press.

Rivers, D. J. (2011). Intercultural processes in accented English. World Englishes. 30(3), 375391.

Sa'd, S. H. T. \& Modirkhameneh, S. (2015). Examining acculturation model in an EFL context: Learners' attitudes towards target language accent vs. L1 accent. GEMA Online ${ }^{\circledR}$ Journal of Language Studies. 15(1), 25-38.

Seidlhofer, B. (2002). The Shape of Things to Come? Some Basic Questions about English as a Lingua Franca. In K. Knapp \& C. Meiercord (Eds.), Lingua franca communication (pp. 269-302). Frankfurt/Main: Peter Lang

Seidlhofer, B. (2011). Understanding English as a Lingua Franca. Oxford: Oxford University Press.

Smith, L. E. (1992). Spread of English and Issues of Intelligibility. In B. B. Kachru (Ed.), The other tongue: English across cultures. Urbana, IL: University of Illinois Press.

Sung, C. C. M. (2014). Global, local or glocal? Identities of L2 learners in English as a Lingua Franca communication. Language, Culture and Curriculum. 27(1), 43-57.

Sung, C. C. M. (2016). Does accent matter? Investigating the relationship between accent and identity in English as a lingua franca communication. System. 60, 55-65.

Tokumoto, M. \& Shibata, M. (2011). Asian varieties of English: Attitudes towards pronunciation. World Englishes, 30(3), 392-408.

Tucker, G. R. \& Lambert, W. E. (1969). White and Negro listeners' reactions to various American-English dialects. Social forces. 47(4), 463-468.

Ushioda, E. \& Dörnyei, Z. (2009). Motivation, Language Identities and the L2 Self: A Theoretical Overview. In Z. Dörnyei \& E. Ushioda (Eds.), Motivation, language identity and the L2 self: Multilingual Matters.

Walker, R. (2010). Teaching the pronunciation of English as a lingua franca: Oxford University Press Oxford.

Wang, W. (2015). Teaching English as an international language in China: Investigating university teachers' and students' attitudes towards China English. System. 53, 60-72.

Wang, Y. (2012). Chinese Speakers' Perception of Their English in Intercultural Communication. (Doctor of Philosophy), University of Southampton.

Xu, W., Wang, Y. \& Case, R. E. (2010). Chinese attitudes towards varieties of English: A preOlympic examination. Language Awareness. 19(4), 249-260.

Yashima, T. (2002). Willingness to communicate in a second language: The Japanese EFL context. The Modern Language Journal. 86(1), 54-66.

Yashima, T., Zenuk-Nishide, L. \& Shimizu, K. (2004). The influence of attitudes and affect on willingness to communicate and second language communication. Language Learning. 54(1), 119-152.

Zeinivand, T., Azizifar, A. \& Gowhary, H. (2015). The relationship between attitude and speaking proficiency of Iranian EFL learners: The case of Darrehshehr city. ProcediaSocial and Behavioral Sciences. 199, 240-247.

Zhang, L. \& Zhao, J. (2014). A Review of Chinese English Accent Studies. Journal of China 
University of Geosciences (Social Sciences Edition). 14(1), 132-138.

Zheng, X. \& Gao, Y. (2017). Language Attitude Education as ICC Facilitation: An Explorative Class. Chinese Journal of Applied Linguistics, 40(1), 3-20.

Zheng, Y. (2013). An inquiry into Chinese learners' English-learning motivational self-images: ENL learner or ELF user? Journal of English as a Lingua Franca. 2(2), 341-364.

\section{ABOUT THE AUTHORS}

Yan Huang is a senior lecturer at the Department of Foreign Languages in Sichuan University of Science and Engineering; a full-time PhD candidate at Asia-Europe Institute, University of Malaya.

Azirah Hashim is a Professor and Executive Director of Asia-Europe Institute, University of Malaya; the vice President of the International Association of Applied Linguistics. 